Pontifícia Universidade Católica $_{\text {a }}$ DO RIO DE JANEIRO

João Pedro Chaves Valladares Pádua

\title{
A NEGOCIAÇÃO DA INTERSUBJETIVIDADE EM DEBATES SOBRE TEXTOS NORMATIVOS NA ASSEMBLÉIA NACIONAL CONSTITUINTE BRASILEIRA DE 1987/88
}

Tese de Doutorado

Tese apresentada ao Programa de Pós-graduação em Estudos da Linguagem da PUC-Rio como requisito parcial para obtenção do título de Doutor em Letras/Estudos da Linguagem.

Orientadora: Profa. Maria do Carmo Leite de Oliveira 

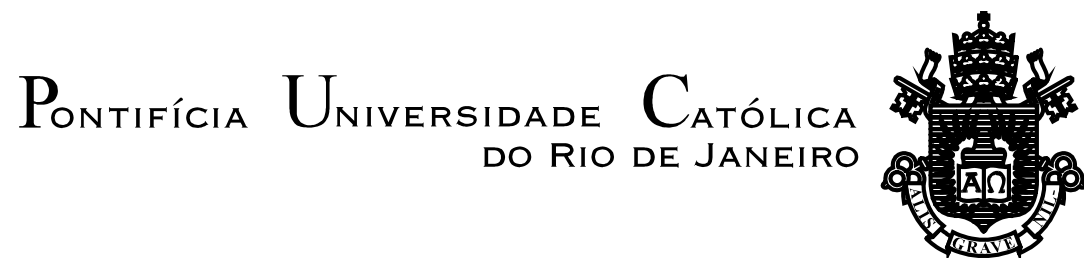

João Pedro Chaves Valladares Pádua

\section{A NEGOCIAÇÃO DA INTERSJUBJETIVIDADE EM DEBATES SOBRE TEXTOS NORMATAIVOS NA ASSEMBLEIA NACIONAL CONSTITUINTE BRASILEIRA DE 1987/88}

Tese apresentada como requisito parcial para obtenção do grau de Doutor pelo Programa de Pós-Graduação em Estudos da Linguagem da PUC-Rio. Aprovada pela Comissão Examinadora abaixo assinada.

Profa. Maria do Carmo Leite de Oliveira

Orientadora

Departamento de Letras - PUC-Rio

Profa. Liliana Cabral Bastos Departamento de Letras - PUC-Rio

Prof. Noel Struchiner

Departamento de Direito - PUC-Rio

Profa. Sonia Bittencourt Silveira UFJF

Prof. Richard Malcolm Coulthard UFSC

Profa. Denise Berruezo Portinari Coordenadora Setorial do Centro de Teologia e Ciências Humanas - PUC-Rio

Rio de Janeiro, 09 de agosto de 2013. 
Todos os direitos reservados. É proibida a reprodução total ou parcial do trabalho sem autorização da universidade, do autor e do orientador.

\section{João Pedro Chaves Valladares Pádua}

Bacharel em Direito, Mestre em Teoria do Estado e Direito Constitucional (PUC-RIO), Doutor em Estudos da Linguagem (PUC-RIO), Professor de Direito Processual Penal (UFF), Advogado.

Ficha Catalográfica

Pádua, João Pedro Chaves Valladares

A negociação da intersubjetividade em debates sobre textos normativos na assembleia nacional constituinte brasileira de 1987/88 / João Pedro Chaves Valladares Pádua ; orientadora: Maria do Carmo Leite de Oliveira. - 2013.

207 f. : il. (color.) ; $5 \mathrm{~cm}$

Tese (doutorado)-Pontifícia Universidade Católica do Rio de Janeiro, Departamento de Letras, 2013.

Inclui bibliografia

1. Letras - Teses. 2. Linguística aplicada das profissões. 3. Discurso. 4. Interação. 5. Linguística forense. 6. Direito. 7. Constituição. 8. Constituinte. 9. Textos normativos. I. Oliveira, Maria do Carmo Leite de. II. Pontifícia Universidade Católica do Rio de Janeiro. Departamento de Letras. III. Título. 
À Professora Maria do Carmo Oliveira, que me ensinou tudo o que pude aprender sobre linguística; e mais algumas coisas sobre vida universitária

À minha mãe, Lena, que faleceu antes de terminar seu mestrado em Letras e agora tem um filho doutor

À minha vó Léa, meu avô João e meu avô Cássio (in memoriam), e minha avó Lúcia, que ajudaram a me criar

À Fernanda, que acaba de me acompanhar e me apoiar no terceiro grande trabalho acadêmico que termino ao seu lado 


\section{Agradecimentos}

Agradecer significa lembrar, com felicidade, mas também significa esquecer, infelizmente e indesculpavelmente. Portanto, o meu primeiro agradecimento vai para quem eu, infelizmente e indesculpavelmente esquecer. Todos os que passaram pela minha vida, acadêmica ou não, me ajudaram de alguma forma e merecem o meu agradecimento.

Agradeço à Professora Maria do Carmo Leite de Oliveira, que começou me acolhendo como aluno extraordinário, me ajudou a fazer um pré-projeto aceitável e acabou por me ensinar tudo o que pude aprender sobre linguística. Agradeço também pela paciência com o meu jeito enrolado e funciona-só-sob-pressão de ser e pelas inúmeras lições sobre vida acadêmica e sobre natureza humana. Agradeço especialmente por me mostrar que o conhecimento que nós produzimos tem de ser útil para alguém, se não, é mero exercício de arrogância intelectual. Na pessoa dela, agradeço também a todas as demais professoras que tive no curso do doutorado, que me ajudaram, cada uma a seu jeito, a entender um campo novo do saber no qual me aventurava pela primeira vez.

Agradeço ao Professor Malcolm Coulthard, ao Professor Noel Struchiner, à Professora Liliana Cabral Bastos e à Professora Sonia Bittencourt Silveira, que gentilmente aceitaram participar da banca desta tese e tanto me ajudaram a engrandecer esse evento acadêmico - como uma defesa de tese deve ser.

Aproveito para agradecer a todos os demais professores que tive, em todos os níveis de ensino, que são corresponsáveis pela vontade que tive de percorrer todos os demais níveis, até o doutorado.

Agradeço às minhas queridas amigas e companheiras de café Carolina Abritta e Liana Biar. Sem vocês, o doutorado não teria tido um décimo da diversão e da riqueza que teve. Certamente as duas ainda me devem um ou dois cafés, mas fica por conta da amizade.

Agradeço a Janaína Matida, Joana Machado, Guilherme Peres, Luiz Paulo 
Guanabara, Mario Miranda Neto, Enzo Bello, que compareceram à defesa da minha tese e representam, por isso, todos os muitos amigos que, contra todos os prognósticos, eu sou muito feliz em ter, dentro e fora da academia.

Agradeço à minha avó Léa Mello, aos meus avôs Cassio de Souza Mello e João de Lima Pádua (todos in memoriam) e à minha avó Lúcia Pádua, que ajudaram a me criar, e me acolheram sempre, especialmente quanto a minha mãe morreu, já há quase duas décadas. A estabilidade familiar que temos é um legado que carrego sempre.

Agradeço à minha mãe, Lena Chaves, com quem a convivência nem sempre foi fácil, mas que sempre batalhou para me criar com dignidade. Seu exemplo de amor ao conhecimento provavelmente me influenciou mais do que eu sou conscientemente capaz de lembrar. Ela, que faleceu quando escrevia a sua dissertação de mestrado em Letras, agora tem um filho doutor em Letras.

Agradeço também a toda a minha família, que agora ganha o sexto doutor. Especialmente à minha tia, Carmelita Dias, que me inseriu no campo de Letras, e sem a qual eu certamente não teria conseguido, como ela, me doutorar nele.

Agradeço, finalmente, à Fernanda. São quase doze anos. Em termos de trabalhos acadêmicos, foram todos os possíveis: ela me viu defender a monografia de graduação, a dissertação de mestrado e a tese de doutorado. Ainda veremos os nossos filhos fazerem o mesmo (se eles quiserem, claro). Todo o meu amor e meu agradecimento pela compreensão nessa época difícil. Çolfa, dibeus! 


\section{Resumo}

Pádua, João Pedro Chaves Valladares; OLIVEIRA, Maria do Carmo Leite de. A negociação da intersubjetividade no debate sobre textos normativos na Assembleia Nacional Constituinte Brasileira de 1987/88. Rio de Janeiro, 2013. 207 p. Tese de Doutorado - Departamento de Letras, Pontifícia Universidade Católica do Rio de Janeiro.

O trabalho visa a compreender os processos, mecanismos e métodos discursivos pelos quais os participantes (parlamentares) de uma Comissão Temática (chamada “Comissão da Soberania e dos Direitos e Garantias do Homem e da Mulher" - CSDGHM) da primeira fase dos trabalhos da última Assembleia Nacional Constituinte brasileira, negociam a aprovação do seu texto final, que vale como o projeto da comissão. Essa pesquisa situa-se numa lacuna da literatura jurídica e linguística: jurídica, porque não há trabalhos no campo do direito que deem conta do nível micro de produção de textos normativos, seus processos e consequências; linguística, porque, mesmo com o avanço notável dos estudos sobre linguagem e direito (também chamados de linguística forense), uma parte dos estudos mais amplos sobre linguística aplicada das profissões, nenhum capítulo desses estudos parece muito preocupado sobre como os textos normativos são criados.

Utilizando ferramentas analíticas dos estudos discursivo-interacionais e da etnometodologia - especialmente os conceitos de intersubjetividade, formulação e account -, este trabalho se baseia na análise de documentos e transcrições oficiais (leigas) de reuniões da CSDGHM, disponíveis em domínio público em páginas dos sites da Câmara dos Deputados e do Senado Federal. Ao todo, foram inicialmente analisados três textos de anteprojetos da CSDGHM e transcrições de 13 reuniões de debates da CSDGHM, além de alguns textos de projetos de emendas ao texto do anteprojeto, por amostragem. Depois da pré-análise, quatro partes do texto do anteprojeto foram selecionadas como guias analíticos para a identificação de fenômenos e processos discursivos-chaves nas reuniões de debates, por terem sido as partes do texto que mais controvérsia geraram nas reuniões de debate da comissão.

A análise demonstrou, em primeiro lugar, que o processo de formação de normas é uma macroatividade, que engloba três tipos de atividades principais - a atividade de redação, a atividade de emendas e a atividade de debates. Esta última 
atividade, a de debates, é a mais visível e mais trabalhosa das três, e o local privilegiado onde são negociados aspectos controvertidos do texto do anteprojeto que está em discussão, em busca de uma intersubjetividade que permita a aprovação do anteprojeto por consenso, por negociação da redação de partes do texto, ou por uma votação polarizada em termos de "sim" ou "não".

Em segundo lugar a análise demonstrou que os participantes negociam a intersbujetividade quanto a texto através de formulações - que negociam o(s) sentido(s) do texto normativo em discussão e seus efeitos na possibilidade aceitação ou rejeição desse texto -; e de accounts - que são usados como instrumentos discursivos de defesa da correção e razoabilidade das posições ideológicas dos participantes, em relação ao texto em discussão e ao(s) seu(s) sentido(s) formulado(s).

Por fim, a análise demonstrou a complexidade do processo de formação de normas, em geral, da atividade de debates, mais particularmente, e dos instrumentos, procedimentos, mecanismos e protocolos utilizados pelos participantes dessa atividade para chegarem a um acordo ou uma votação sobre o texto a ser aprovado, ainda mais particularmente.

Implicações para futuras pesquisas (nesse e em outros campos jurídicos e da linguística aplicada das profissões) são discutidas, em considerações finais.

\section{Palavras-chave}

Linguística aplicada das profissões; Discurso; Interação; Linguística Forense; Direito; Constituição; Constituinte; Textos normativos; Legislativo; Criação de normas jurídicas. 


\section{Abstract}

Pádua, João Pedro Chaves Valladares; OLIVEIRA, Maria do Carmo Leite de (Advisor). Intersubjectivity Negotiation in Debates over Normative Texts in The Brazilian National Constitutional Assembly of 1987/88. Rio de Janeiro, 2013. 207 p. PhD Thesis - Departamento de Letras, Pontifícia Universidade Católica do Rio de Janeiro.

This research aims at understanding the discursive processes, mechanisms and methods whereby participants (members of parliament) of a Thematic Committee (called Comissão da Soberania e dos Direitos e Garantias do Homem e da Mulher - CSDGHM, or Committee on the Sovereignty, Rights and Guaranties of Men and Women) from the first phase of the last Brazilian Constitutional Assembly negotiate the approval of its final text, that counts as the (normative) project of the committee. This research situates itself in a gap of both the juridical and linguistics literature: juridical, because there is no work in the field of law that account for the micro level of the production of normative texts, its processes and consequences; linguistics, because, notwithstanding the notable development of the studies on Language and Law (also called Forensic Linguistics), a part of the more general studies on Applied Linguistics of Professions, no chapter of these studies seem much concerned with how normative texts are created.

Using analytical framework from interactional-discursive studies and ethnomethodology - especially the concepts of intersubjectivity, formulation and account - , this research stems from the analysis of documents and official (lay) transcriptions of CSDGHM's meetings, available to public domain from websites of the Brazilian Camara dos Deputados (House of Representatives) and Senado Federal (Federal Senate). Overall, texts from three versions of the committee's project, transcripts from 13 meetings and some text from amendment propositions were initially analyzed. After this pre-analysis, for parts of the projects' texts were selected as analytical guides to the spotting of key discursive phenomena and processes in the debate meetings, because these parts of the project were the most subjected to controversy in those meetings.

Analysis has shown, first, that the process of norm-enacting is a 
macroactivity, which encompasses three main types of activities - the drafting activity, the amendment activity and the debate activity. This last activity debate activity - is the most visible and most difficult of the three, and as such, is the privileged locus where controversial aspects of the text of the committee's project are negotiated, in search of a intersubjectivity that allows for the approval of that project, either by consensus, bargaining on parts of the text, or by a polarized vote in terms of "yes" ou "no".

Second, analysis has shown that participants negotiate intersubjectivity about the text through formulations - which negotiate the sense/s of the normative text under discussion and its effects on the possibility of accepting or rejecting this text -; and through accounts - which are used as discursive instruments to defend the correction or reasonableness of the ideological positions of the participants, with regard to the text under discussion and its/their formulated sense/s.

Finally, analysis has shown the complexity of the process of normenacting, in general, of the debate activity, more particularly, and of the instruments, procedures, mechanisms and protocols used by participants of these activities to reach an agreement or a vote on the text to be approved, even more particularly.

\section{Keywords}

Applied linguistics of professions; Discourse; Interaction; Forensic Linguistics; Law; Constitution; Constitutional Assembly; Normative texts; Legislative; Juridical norm-enacting. 


\section{Sumário}

Introdução

Cap. 1. Teoria e metodologia

Cap. 2. O Processo de formação de normas jurídicas (na Assembleia Nacional Constituinte de 1987/88)

Cap. 4. Formulações (discussões sobre sentidos possíveis do texto)

Cap. 5. Accounts (discussões sobre um dado sentido do texto)

Cap. 6. Genealogia da intersubjetividade: O caso do texto da regulamentação da propriedade privada 


\section{Lista de Siglas e Abreviaturas}

Ab. - Artigo do texto do (ante)projeto do relator sobre direitos do nascituro e aborto

ANC - Assembleia Nacional Constituinte

CSDGH - Comissão da Soberania e dos Direitos e Garantias do Homem e da Mulher (da Assembleia Nacional Consituite)

DC - Artigo do texto do (ante)projeto do relator sobre direito e liberdade de culto

OS - Artigo do texto do (ante)projeto do relator sobre orientação sexual PP - Artigo do texto do (ante)projeto do relator sobre propriedade privada RIANC - Regimento Interno da Assembleia Nacional Constituinte 


\section{Lista de Tabelas e Figuras}

Tabela 1.1. Etapas da ANC

Tabela 1.2. Dados iniciais recolhidos para análise

Tabela 1.3. Manifestações sobre textos analisados, separados por texto e por constituinte.

Tabela 1.4. Exemplo de texto do (ante)projeto separado para análise

Tabela 1.5. Dados finais separados e consolidados

Tabela 4.1. Tipos e Mecanismos de Formulações

Tabela 5.1. Tipos e Mecanismos de Accounts

Tabela 6.1. Quantitativo de tipos e mecanismos de accounts e formulações na análise dos discursos sobre PP

Tabela 6.2. Quantitativo de manifestações a favor ou contra o texto do (ante)projeto sobre PP

Tabela 6.3. Comparativo dos textos das três versões do (ante)projeto relativos ao artigo sobre PP

Tabela 6.4. Comparativo do textos das duas últimas versões do (ante)projeto sobre PP

Figura 2.1. Esquema de etapas do processo de formação de normas Figura 2.2. Esquema de atividades envolvidas no processo de formação de normas

Figura 3.1. Estrutura de participação na atividade de debates 